\title{
Solar Farm Site Selection Using Spatial Multi Criteria Evaluation Method: Acase Study of Kewet Wereda, North-Center Ethiopia.
}

Gashaw Kibret Goshem ( $\square$ lijigashu@gmail.com )

Dilla University https://orcid.org/0000-0001-9894-7419

Binyam Tesfaw Hailu

Addis Ababa University College of Natural Sciences

\section{Research Article}

Keywords: Solar radiation, Spatial Multi criteria Evaluation Method, Solar farm site selection, Kewet wereda.

Posted Date: January 27th, 2022

DOl: https://doi.org/10.21203/rs.3.rs-1007080/v1

License: (c) (i) This work is licensed under a Creative Commons Attribution 4.0 International License.

Read Full License 


\section{Abstract}

Solar energy can provide a great opportunity for alternative energy source and development of the nation of the country. It can access freely throughout earth's surface so, solar energy is the best alternative energy source for solving limitation of power especially when there is drought. Therefore, this thesis aims to select suitable solar farm sites by using spatial multi criteria evaluation method in Kewet Wereda. Different spatial and non-spatial data such as solar radiation, slope, aspect, LULC, proximity distance to road, proximity distance to sub-station site, proximity distance to river, proximity distance to railway and proximity distance to town have been used to identify and map area. Some parameter data are taken from 30 meter resolution of DEM such as solar radiation, slope, aspect and river streams. Analytical Hierarchy process (AHP) was used for

Calculation of the criteria weighted overlay to produce a suitable solar farm site map. The result shows that solar radiation has the highest weight and distance to river has the lowest weight with $36.6 \%$ and $3.4 \%$, respectively. In addition, optimal solar farm sites were identified and highly suitable area found in the south, southeast and northeast part of the study area and covers 35988.71 hectare area. Those potential zone contributes to fill the energy gap between the demand and supply of the country when there is a shortage of rainfall through the country and shortage of water at the dam.

\section{Introduction}

Solar energy is vast, free, clean and renewable power source that is available everywhere on the planet[1]. The energy stored in the fossil fuels which we burn originated from the sun when they formed[2].

Energy is a critical part of modern life as almost all human activities are strongly connected with it [3]. Although in the current economic situation, the rational use of the available resources and the need to overcome the undesirable environmental effects and other problems associated with fossil fuels have forced many countries to enquired into and change to more environmentally friendly alternatives which are renewable in order to sustain the increase energy demand and potential availability of solar energy differs from region to region in the word because of geographical location and world climate zones [4].

GIS is a powerful tool for recognizing suitable site selection, for consulting, editing, analyzing and reduce risk costs of large solar energy investments [5]. In this era, GIS-based spatial multi criteria evaluation method had become gradually popular as a tool for different site selection studies especially in the energy planning [6].

Ethiopia is located in the horn of Africa and among one of the fastest developing nations on the continent. In terms of population, the country is home to over 110 million people, which makes it the second most populous country in Africa behind Nigeria and just ahead of Egypt. As a result of Ethiopia's rapid population over the past decade, the electricity demand has also been increasing gradually. The electricity generation capacity approximately $90 \%$ of the installed generation of electricity is from hydropower while the remaining $8 \%$ and $2 \%$ are from wind and thermal sources respectively[7]. Even if the 
country has bulk electric power resource potential in nonrenewable and renewable energy resources, these have insufficient access to all the Ethiopian regions, zones and other administrative areas [8]. Most remote areas such as Kewet wereda where there is drought or the amount of dam water is become decline impossible to get adequate electric energy. Therefore, the study aimed to select solar farm sites by determining solar radiation from 30 meter resolution DEM using spatial multi criteria evaluation method.

\section{Materials And Methods}

\subsection{Study area description}

Kewet is one of the wereda at the North-Center part of Ethiopia. It is located at $225 \mathrm{~km}$ northeast of Addis Ababa in the northern Shewa Zone Amhara Region. Shewa Robit is one of it's the major town, it has an altitude of about 1,280 meters above sea level (m.a.s.l). The Wereda lies at a longitude and latitude of $39.744^{\circ} \mathrm{E}, 10.167^{\circ} \mathrm{N}$. It is bounded on the north by Efratana Gidim, on the northwest by Menzmammidir on the east by Afar Region and on the southwest by Termaber[9]. Total area 785.85 square kilometers, population number based on 2007 national censuses over 118,381 population and have hot weather condition through the year.

\subsection{Data source}

Table 1

data source

\begin{tabular}{|lllll|}
\hline SN. & Dataset & Format & Sources & Resolution \\
\hline 1 & SRTM & Raster & (https://earthdata.nasa.gov/) & $30 \mathrm{M}$ \\
\hline 2 & Solar radiation & Raster & Digital elevation model & $30 \mathrm{M}$ \\
\hline 3 & Landsat8 & Raster & https://earthdata.nasa.gov & $30 \mathrm{M}$ \\
\hline 4 & Meteorological data & Float & National meteorological agency & NA \\
\hline 5 & Road network & Vector & Ethiopian Roads Authority & NA \\
\hline 6 & Boundary shape file & Vector & Ethiopian Geospatial Information institute & NA \\
\hline 7 & Railway & Vector & Ethiopian Railway Corporation & NA \\
\hline 8 & Sub-station site & Vector & Ethiopian power cooperation & NA \\
\hline 9 & River & Raster & By delineating digital elevation model & 30 M \\
\hline 10 & GPS data & Float & Field survey & NA \\
\hline
\end{tabular}




\subsection{Software}

Table 2: Software

\begin{tabular}{|ll|}
\hline Software & Utilization \\
\hline ARCGIS10.8 & $\begin{array}{l}\text { Manipulation, analysis, visualization, storage, modeling and } \\
\text { Map preparation. }\end{array}$ \\
\hline ERDAS IMAGINE 2014 & Preprocessing and Classification of LULC. \\
\hline QGIS 3.10 & downloading data, processing of sentinel data \& classification \\
\hline
\end{tabular}

\subsection{Methods}

\subsubsection{GIS-AHP based approach for suitable solar farm site selection}

Nowadays, analysis of land-use suitability requires consideration of different criteria including not only the natural / physical capacity of a land unit but also socio-economic and environmental effects[10].

AHP has specific application in group decision making, and was used all over the world indifferent decision situations, in fields such as, industry area ,government sector, healthcare sector, business area, shipbuilding, site suitability selection and education [11]. Somewhat recommending a "precise" judgement, AHP aids for decision makers delivering best generation for their goals and their understanding of the problem[12]. The essentials of the order be able to join to any feature of the conclusion difficult touchable or intangible, wisely dignified or approximately expected, fit or unwell assumed everything at totally that applies to the choice [13]. 
Table 3

Mapping factors and their Importance

\begin{tabular}{|c|c|}
\hline $\begin{array}{l}\text { Mapping } \\
\text { factors }\end{array}$ & Importance for Mapping \\
\hline Solar radiation & $\begin{array}{l}\text { For identifying the surrounding area average daily receiving solar energy in } \\
\mathrm{Kwh} / \mathrm{m}^{2} \text {. }\end{array}$ \\
\hline $\begin{array}{l}\text { Land } \\
\text { use/cover }\end{array}$ & To know types of land covering through the study area. \\
\hline $\begin{array}{l}\text { Sub-station } \\
\text { site }\end{array}$ & For identifying its economical distance from the sub-station site \\
\hline Road network & For identifying its economical distance from the roads. \\
\hline River & For identifying its proximity from the rivers. \\
\hline Railway & For identifying its economical distance from the railway \\
\hline Slope & For identifying the land surface of the area \\
\hline Aspect & For identifying the direction /azimuths \\
\hline Town & For identifying its proximity distance from the town. \\
\hline
\end{tabular}

\subsubsection{Pairwise comparison matrix}

It is a method which has commonly used to challenge the individual and unbiased decisions around qualitative and quantitative measures in multi-criteria decision making, especially in the Analytical Hierarchy Process (AHP) denoted as pairwise comparison matrices [14].

Evaluation of Matrix Consistency

The consistency ratio was calculated by the following formulas.

$\mathrm{Cl}=(\lambda-n) /(n-1)$

The $\mathrm{Cl}$ stand for Constancy Index, deliver a measure of departure from constancy, to determine the goodness of $\mathrm{Cl}$, AHP compares with it by using the random index.

$\mathrm{CR}=\mathrm{Cl} / \mathrm{RI}$

$\mathrm{CR}$ means constancy ration and Random index (RI) the $\mathrm{Cl}$ of a randomly created pairwise comparison matrix of order 1 to 10 obtained by approximating random indices using a sample size 0 f 500 , (Table 4) shows the value of RI sorted by the order of the matrix. 
Table 4

Random index

\begin{tabular}{|lllllllllll|}
\hline Order Matrix & $\mathbf{1}$ & $\mathbf{2}$ & $\mathbf{3}$ & $\mathbf{4}$ & $\mathbf{5}$ & $\mathbf{6}$ & $\mathbf{7}$ & $\mathbf{8}$ & $\mathbf{9}$ & $\mathbf{1 0}$ \\
\hline $\mathrm{RI}$ & 0.00 & 0.00 & 0.58 & 0.9 & 1.12 & 1.24 & 1.32 & 1.41 & 1.45 & 1.49 \\
\hline
\end{tabular}

\section{Results}

\subsection{Land use land cover Classification}

Figure 3 shows the distribution of each LULC map of the study area. The LULC of the study area is covered by the agriculture (45\%), shrubs (16\%), mixed forest (6\%), built-up areas (21\%), barely lands ( $9 \%$ ) and water body (3\%) (Table 5).

Table 5

Area coverage of classified LULC map

\begin{tabular}{|lll|}
\hline Land cover classes & Area in Km2 & Area Percentage (\%) \\
\hline Water Body & 22.550 & 3 \\
\hline Built up areas & 167.517 & 21 \\
\hline Bare land & 68.670 & 9 \\
\hline Shrubs & 124.783 & 16 \\
\hline Mixed forest & 51.520 & 6 \\
\hline Agriculture & 350.800 & 45 \\
\hline Total & 785.84 & 100 \\
\hline
\end{tabular}

\subsection{Parameters of solar farm site suitability analysis}

\section{A. Reclassified Slope}

Figure 4 shows the suitability map of the slope. There are high relations between slope and solar farm site selection which indicate that the slope less than 15 degree were good such that $<3$ degree is highly suitable from 3 up to 5 degrees is suitable, from 5 to 15 degrees is less suitable but greater than 15 degrees taken as unsuitable because of its economic factors (Table 6). 
Table 6

Reclassified Slope values

\begin{tabular}{|ll|}
\hline Values (degree) & Suitability range \\
\hline $0-3$ & Highly suitable \\
\hline $3-5$ & Suitable \\
\hline $5-15$ & Less suitable \\
\hline $15-53$ & Unsuitable \\
\hline
\end{tabular}

\section{B. Reclassified Aspect}

Figure 5 shows suitability map of aspect of the study area. High solar radiation received in the orientation of respectively flat area, south, south east and southwest, but east - face and west-face are medium potential and north, northeast and northwest taken low potential (Table 7).

Table 7

Reclassified Aspect dataset

\begin{tabular}{|ll|}
\hline Orientation (degrees) & Suitability \\
\hline Flat, South & High suitability \\
\hline Southeast, Southwest & Suitable \\
\hline East, West & Less suitability \\
\hline North, Northeast, Northwest, & Unsuitable \\
\hline
\end{tabular}

D. Distance to Road

Figure 6 shows the suitability distance of the road. The road proximity to the solar farm site is divided based on its economical factor, so $<500$ meter highly suitable, $500-1000 \mathrm{~m}$ suitable, $1000-1500 \mathrm{~m}$ less suitable and $>1500$ meter taken as unsuitable (Table 8 ). 
Table 8

Reclassified distances of roads

\begin{tabular}{|ll|}
\hline Values in meters & Suitable Range \\
\hline $0-500$ & Highly suitable \\
\hline $500-1000$ & Suitable \\
\hline $1000-1500$ & Less suitable \\
\hline$>1500$ & Unsuitable \\
\hline
\end{tabular}

C. Distance to Sub-station

Figure 7 shows suitability map of sub-station. Proximity of the sub-station was taken 0-500 highly suitable area, 500-1500 suitable, $1500-2500$ less suitable and $>2500$ taken as unsuitable (Table 9).

Table 9

Reclassified distance of sub-station

\begin{tabular}{|ll|}
\hline Values in meters & Suitability Range \\
\hline $0-500$ & Highly suitable \\
\hline $500-1500$ & Suitable \\
\hline $1500-2500$ & Less suitable \\
\hline$>2500$ & Unsuitable \\
\hline
\end{tabular}

E. Distance to River

Figure 8 shows suitability of distance of river. Highly suitable (>1500 meter), suitable (1000-1500), less suitable (500-1000) and less than 500 taken as unsuitable. 
Table 10

Reclassified Distance of River

\begin{tabular}{|ll|}
\hline Values in meters & Suitability range \\
\hline $0-500$ & Unsuitable \\
\hline $500-1000$ & Less suitable \\
\hline $1000-1500$ & Suitable \\
\hline$>1500$ & Highly suitable \\
\hline
\end{tabular}

F. Distance to Railway

Figure 9 shows suitability map of railway.

Proximity distance to railway $<500$ meter high suitable, 500-1000 meter suitable, from 1000-1500 less suitable and $>1500 \mathrm{~m}$ unsuitable distances to railway (Table 11).

Table 11

Reclassified Distance to Railway

\begin{tabular}{|ll|}
\hline Values in meters & Suitability range \\
\hline $0-500$ & Highly suitable \\
\hline $500-1000$ & Suitable \\
$1000-1500$ & Less Suitable \\
$>1500$ & Unsuitable \\
\hline
\end{tabular}

H. Distance to Town

Figure 10 shows suitability proximity distance map of the town. Highly suitable $(>6 \mathrm{~km})$, suitable (4-6km), less suitable (2-4km) and unsuitable ( $<2 \mathrm{~km})$ (Table 12$)$.

Table 12

Reclassified Distance to town

\begin{tabular}{|ll|}
\hline Values in meters & Suitability range \\
\hline $0-2000$ & Unsuitable \\
\hline $2000-4000$ & Less suitable \\
$4000-6000$ & Suitable \\
$>6000$ & Highly suitable \\
\hline
\end{tabular}


G. Reclassified Solar Radiation

Figure 11 shows suitability map of solar radiation. (Table 13) indicates suitability range.

Table 13

Reclassified Values of Solar Radiation

\begin{tabular}{|ll|}
\hline Values in $\mathbf{k W h} / \mathbf{m} 2$ per year & Suitability range \\
\hline$>1900$ & Highly suitable \\
\hline $1600-1900$ & Suitable \\
\hline $1300-1600$ & Less suitable \\
\hline$<1300$ & Unsuitable \\
\hline
\end{tabular}

I. Classified Land use land cover

\subsubsection{Weight derivation using pairwise comparison matrices}

Table 14

the weight result for the criteria from pairwise comparisons

\begin{tabular}{|llll|}
\hline S.NO. & Criteria & Priority & Rank \\
\hline 1 & Solar radiation & $36.6 \%$ & 1 \\
\hline 2 & Aspect & $17.3 \%$ & 2 \\
\hline 3 & Slope & $13.1 \%$ & 3 \\
\hline 4 & LULC & $8.2 \%$ & 4 \\
\hline 5 & Railway & $5.9 \%$ & 5 \\
\hline 6 & Sub-station site & $5.7 \%$ & 6 \\
\hline 7 & Town & $5 \%$ & 7 \\
\hline 8 & Road & $4.8 \%$ & 8 \\
\hline 9 & River & $3.4 \%$ & 9 \\
\hline
\end{tabular}


Table 15

the weight result of decision matrix based on the principal Eigenvector

\begin{tabular}{|lllllllllll|}
\hline S.NO & Criteria & $\mathbf{1}$ & $\mathbf{2}$ & $\mathbf{3}$ & $\mathbf{4}$ & $\mathbf{5}$ & $\mathbf{6}$ & $\mathbf{7}$ & $\mathbf{8}$ & $\mathbf{9}$ \\
\hline 1 & S.radiation & $\mathbf{1}$ & 5.00 & 3.00 & 3.00 & 9.00 & 7.00 & 7.00 & 3.00 & 9.00 \\
\hline 2 & Aspect & 0.20 & $\mathbf{1}$ & 2.00 & 4.00 & 5.00 & 3.00 & 3.00 & 3.00 & 3.00 \\
\hline 3 & Slope & 0.33 & 0.50 & $\mathbf{1}$ & 2.00 & 5.00 & 3.00 & 2.00 & 3.00 & 2.00 \\
\hline 4 & LULC & 0.33 & 0.25 & 0.50 & $\mathbf{1}$ & 2.00 & 2.00 & 2.00 & 2.00 & 2.00 \\
\hline 5 & Railway & 0.11 & 0.20 & 0.20 & 0.50 & $\mathbf{1}$ & 2.00 & 2.00 & 2.00 & 2.00 \\
\hline 6 & Sub-station & 0.14 & 0.33 & 0.33 & 0.50 & 0.50 & $\mathbf{1}$ & 1.00 & 2.00 & 4.00 \\
\hline 7 & Town & 0.14 & 0.33 & 0.50 & 0.50 & 0.50 & 1.00 & $\mathbf{1}$ & 1.00 & 2.00 \\
\hline 8 & Road & 0.33 & 0.33 & 0.33 & 0.50 & 0.50 & 0.50 & 1.00 & $\mathbf{1}$ & 2.00 \\
\hline 9 & River & 0.11 & 0.33 & 0.50 & 0.50 & 0.50 & 0.25 & 0.50 & 0.50 & $\mathbf{1}$ \\
\hline
\end{tabular}

\section{Discussions}

GIS and different geospatial technology are used for analysis and combination of different features that are used to indicate suitable solar farm sites. The study have used different vector and raster data format such as Landsat data, road, sub-station, railway and digital elevation model. DEM has great factor for study to estimate the study areas solar radiation and almost all the environmental factors are drive from it, such as slope, aspect, and solar radiation and river streams. The estimated solar radiation depended on the resolution of DEM as well as the parameters such as time interval and sky size resolution[15]. Higher resolution with smaller time interval and bigger sky size results more accurate output, but also increases considerable calculation time.

GIS-based spatial multi criteria evolution method applied to select the ideal location for selecting a suitable solar farm site at kewet wereda. In addition to solar radiation potential, various topography, economic and environmental factors were taken into considering in the site selection process. As environmental (solar radiation, aspect, slope), economical (proximity to road, proximity to sub-station, proximity to the railway, proximity to the river and proximity to town). The accuracy assessments and the weighted of the study area were both have acceptable values.

[16]Kappa value 0.81 up to one indicts almost has perfect agreements. The study area accuracy assessment done with 351 points based on this points the accuracy, verify by field survey, google earth and google map and we generate $87.7 \%$ of overall accuracy and kappa value $81 \%$ which match with our study area so, it was acceptable to do further analysis. According to[17], the AHP pairwise comparison CR value less than 0.1 was acceptable. So, the study weight derived from the AHP pairwise comparison method its CR value 0.07 which was less than 0.1 and the weight was acceptable. 
In the same title [18] was also used a multi-criteria approach in his GIS analysis to select suitable solar farm site throughout Ethiopia. By using six criteria and with low resolution satellite image and his study area coverage was very large. Which included all Ethiopian area so, in case of wide area coverage the researcher was verified the accuracy assessments with google earth and google map. Because of this, the researcher have poor accuracy classification and less accurate result, but in this study which differ from Teshome the coverage of the study area was limited and which have done with nine criteria and with 30 meter resolution of satellite image and the accuracy of the study area classification was verified by field trip, high resolution satellite image, google earth and google map which have acceptable classification and good result.

[19]was estimated the solar radiation from six stations measured data by using interpolation methods and mapped the Ethiopian solar energy distribution, in addition [20]was estimated the solar radiation from 17 stations measured data by interpolating to know the solar energy potential of Ethiopia. [21]unlike temperature and rainfall, solar radiation cannot be measured at sample meteorological stations and cannot be interpolated for the surrounding areas.

This is mostly since incoming solar radiation is extremely dependent on landscape and geographical structure[22].Tesfay and Sharew was identified and mapped the solar energy of Ethiopian with a few stations by interpolation with all Ethiopia's topography features from the lowest depression (-125 meter) to the highest elevation (4550 meter), because of this, their result is less necessary. But this study differ from both of them with methods, coverage area and data usage, this thesis was cover less area and done with determining solar radiation by using 30 meter resolution satellite data which contain all the topography of the study area and determine good solar radiation value with using nine criteria such as based on economic factors(road, sub-station, railway, river ,town ,LULC) and environmental factors (solar radiation, slope, aspect) were used to do this study.

\section{Conclusions}

The result shows that solar radiation has the highest weight and distance to river has the lowest weight with $36.6 \%$ and $3.4 \%$. Although from total area of 78580 hectares an optimal location area was selected 35988.71 hectares and highly suitable $6 \%$, Suitable $40 \%$, less suitable $44 \%$ and Unsuitable $10 \%$ areas were covered. The most potential of solar farm sites are found in the south, southeast and northeast parts of the study area. Those potential zone contributes to fill the energy gap between the demand and supply of the country when there is a shortage of rainfall through the country and shortage of water at the dam.

\section{Declarations}

\section{Acknowledgements}


We would like thank the contribution of Indian institute of Space Science and Technology, United States Geological Survey and Ethiopian geospatial institute by accessing freely their geospatial data for preparing this study.

\section{References}

[1] C. Salame, M. Aillerie, P. Papageorgas, (2015).

[2] I. Piirisaar, Master Thesis Geogr. Inf. Sci. (2019).

[3] D. Kereush, I. Perovych, Geomatics, Landmanagement Landsc. (2017).

[4] A. Georgiou, D. Skarlatos, Geosci. Instrumentation, Methods Data Syst. 5 (2016) 321-332.

[5] M. Otgonbayar, C. Atzberger, J. Chambers, D. Amarsaikhan, S. Böck, J. Tsogtbayar, J. Geosci. Environ. Prot. 5 (2017) 238.

[6] M. Abdelrazek, M. Sc. Geoinformatics, Univ. Salzburg, Thesis Austria (2017) 1-84.

[7] H. Lakew, B. Hailu, T. Hailu, S. Carter, (2017).

[8] E.M. Getie, J. Electr. Comput. Eng. 2020 (2020).

[9] kewet woreda, Rom Wikipedia, Free Encycl. (2021).

[10] E. Noorollahi, D. Fadai, M. Akbarpour Shirazi, S.H. Ghodsipour, Energies 9 (2016) 643.

[11] T.L. Saaty, Oper. Res. 61 (2013) 1101-1118.

[12] H. Madurika, G. Hemakumara, Int. J. Sci. Technol. Res. 6 (2017) 96-105.

[13] S.-H. Kil, D.K. Lee, J.-H. Kim, M.-H. Li, G. Newman, Sustainability 8 (2016) 58.

[14] G. Kou, D. Ergu, C. Lin, Y. Chen, Technol. Econ. Dev. Econ. 22 (2016) 738-765.

[15] F. Umer, M.S. Aslam, M.S. Rabbani, M.J. Hanif, N. Naeem, M.T. Abbas, Int. J. Photoenergy 2019 (2019).

[16] S.S. Rwanga, J.M. Ndambuki, Int. J. Geosci. 8 (2017) 611.

[17] R.W. Saaty, Math. Model. 9 (1987) 161-176.

[18] F. Teshome, Nor. Univ. Sci. Technol. (2014).

[19] T. Bayou, Zede J. 13 (1996) 48-60.

[20] S.A. Mekonnen, Environ. Sci. Addis Ababa Univ. Addis Ababa, Ethiop. (2007). 
[21] L. Kumar, A.K. Skidmore, E. Knowles, Int. J. Geogr. Inf. Sci. 11 (1997) 475-497.

[22] A. Gastli, Y. Charabi, in: 2010 IEEE Int. Energy Conf., IEEE, 2010, pp. 548-552.

\section{Figures}

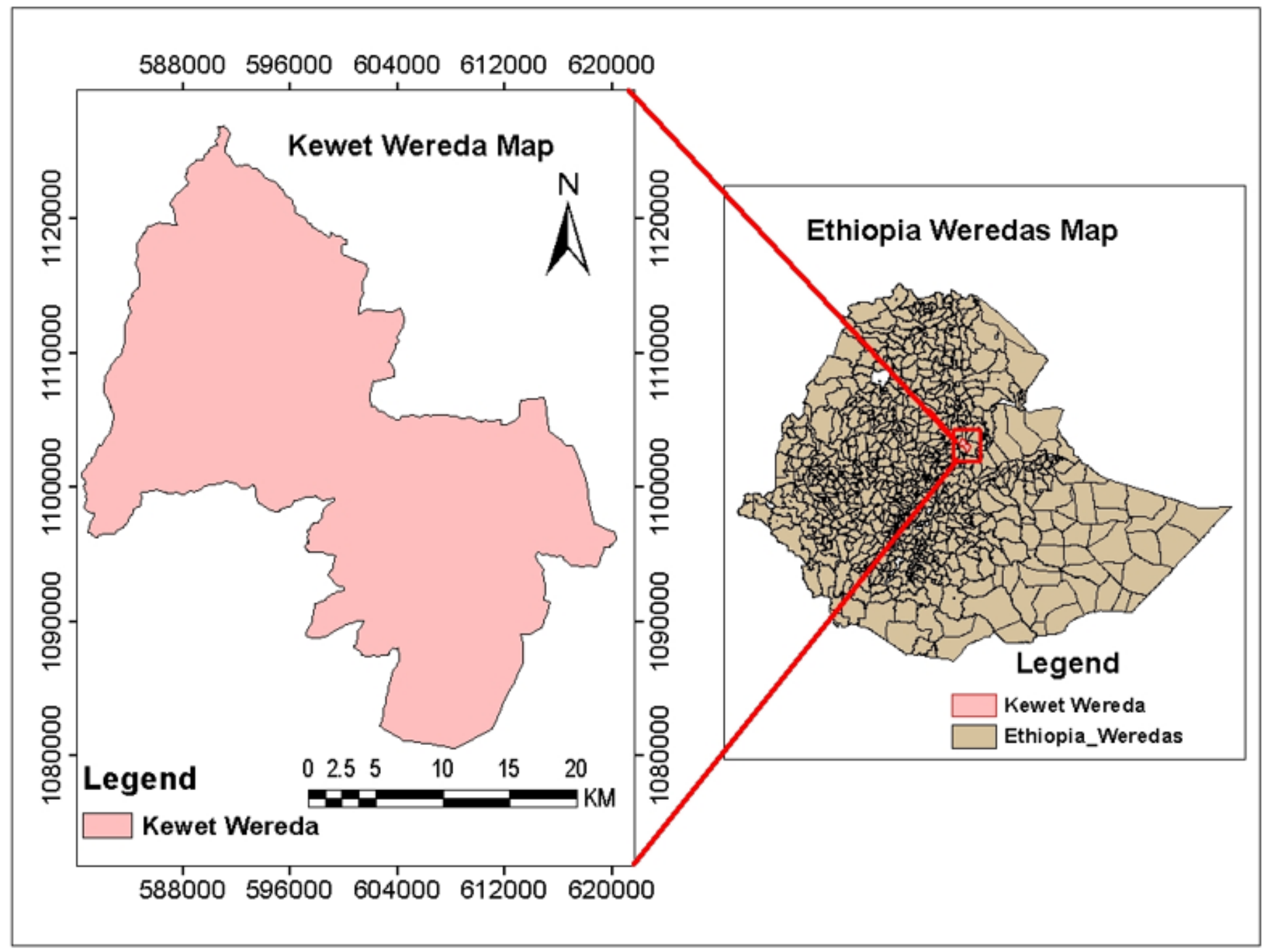

Figure 1

Location map of the Study area 


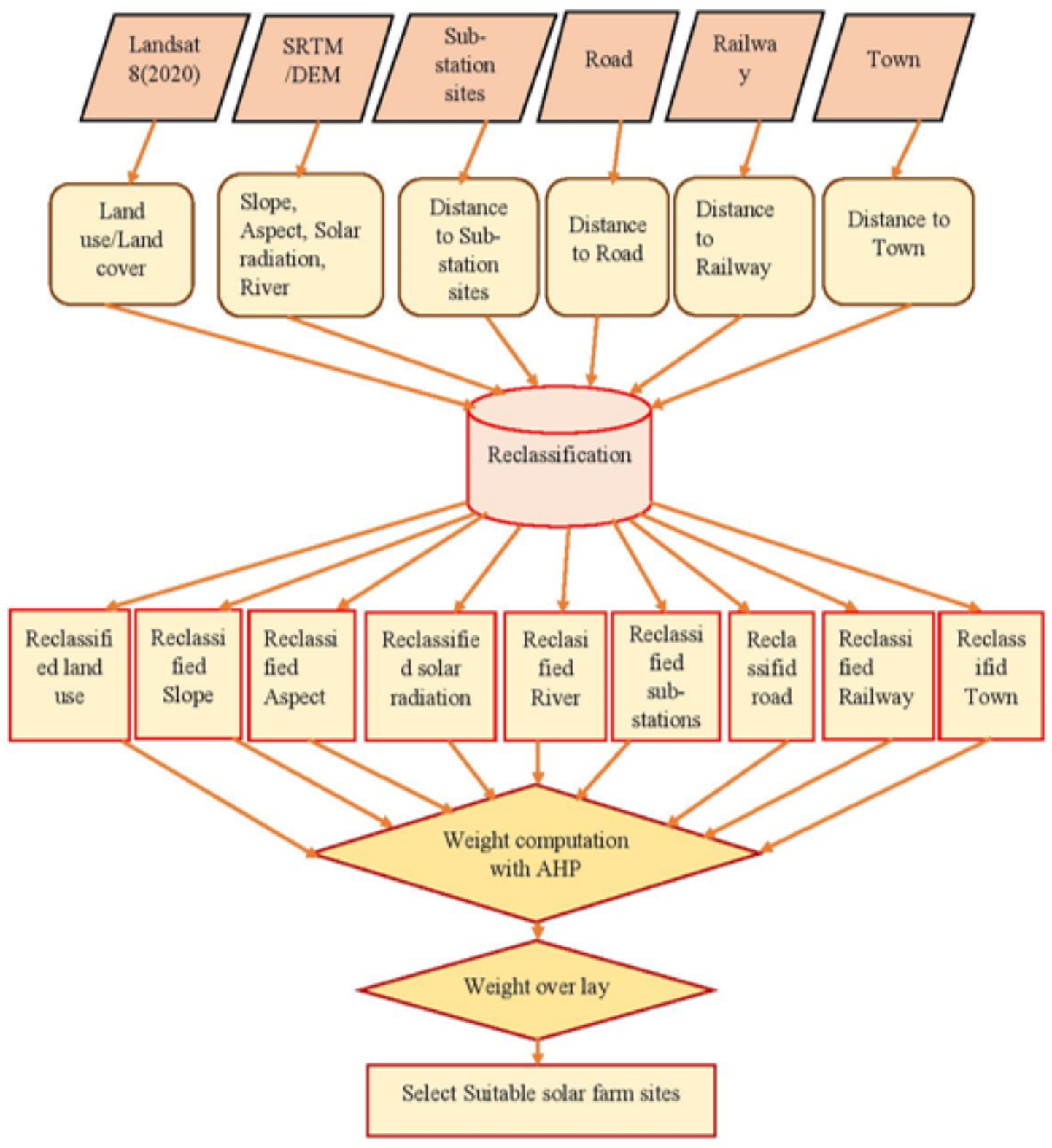

Figure 2

General work flow the study 


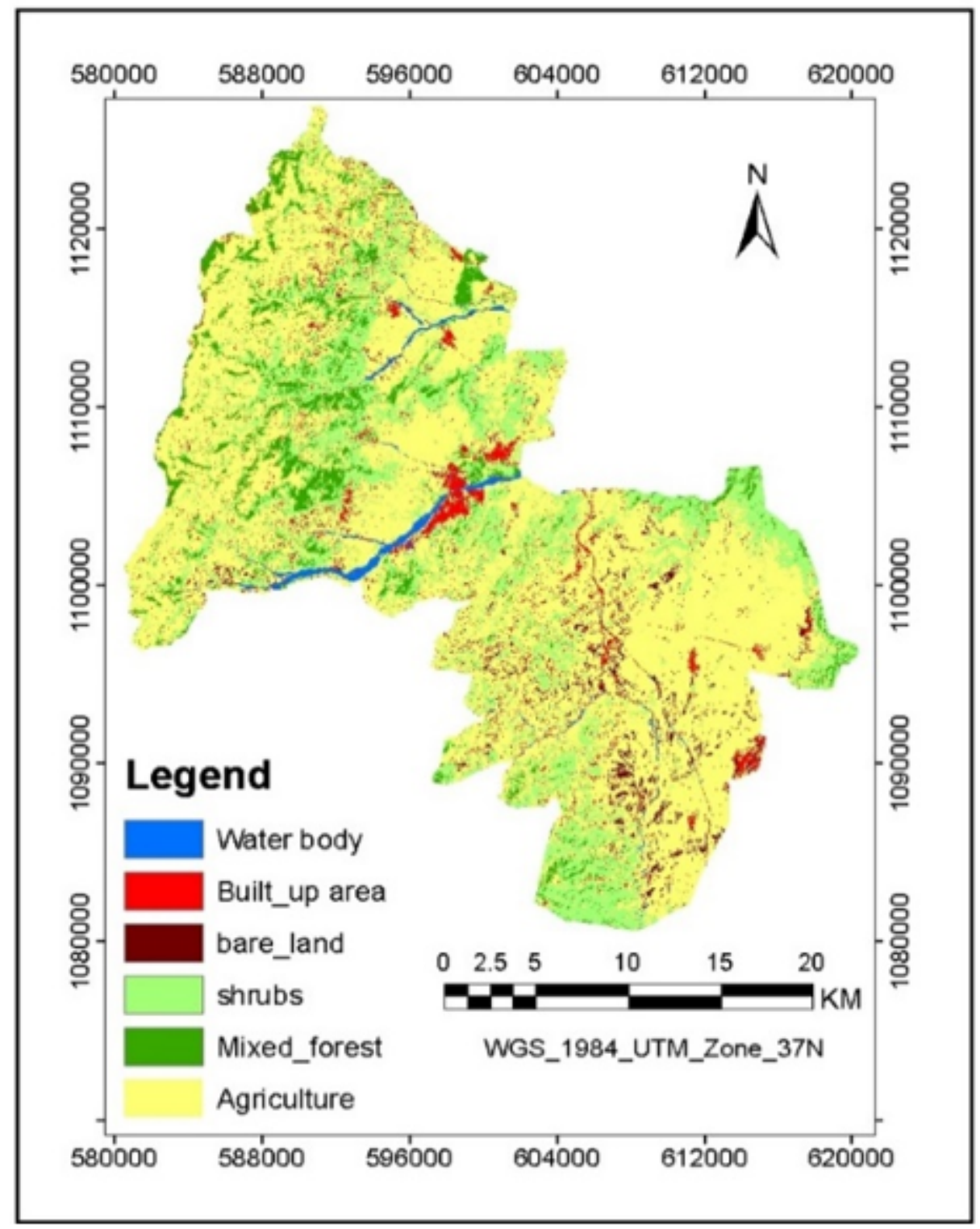

Figure 3

land use/ land cover classification 


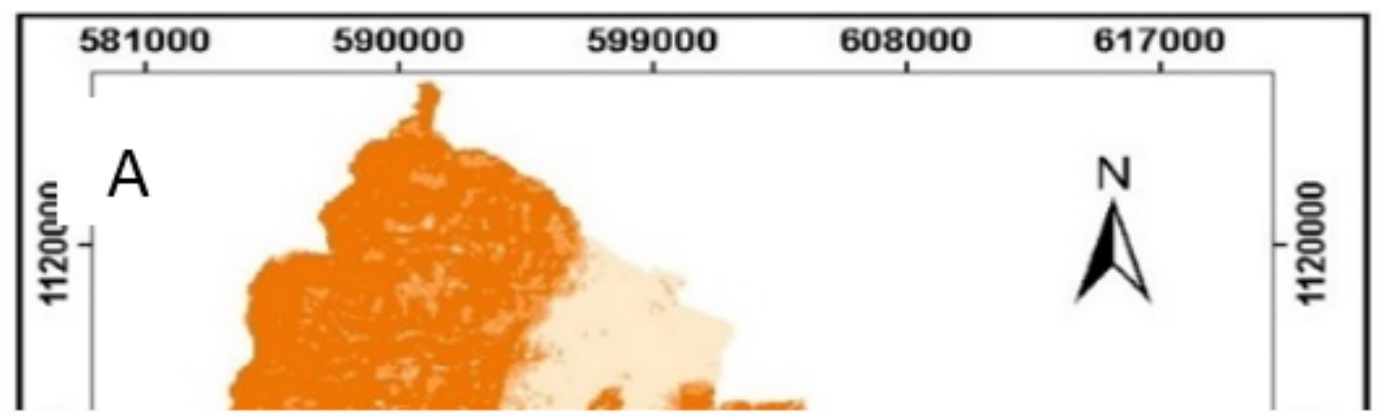

Figure 4

Suitability map of slope 


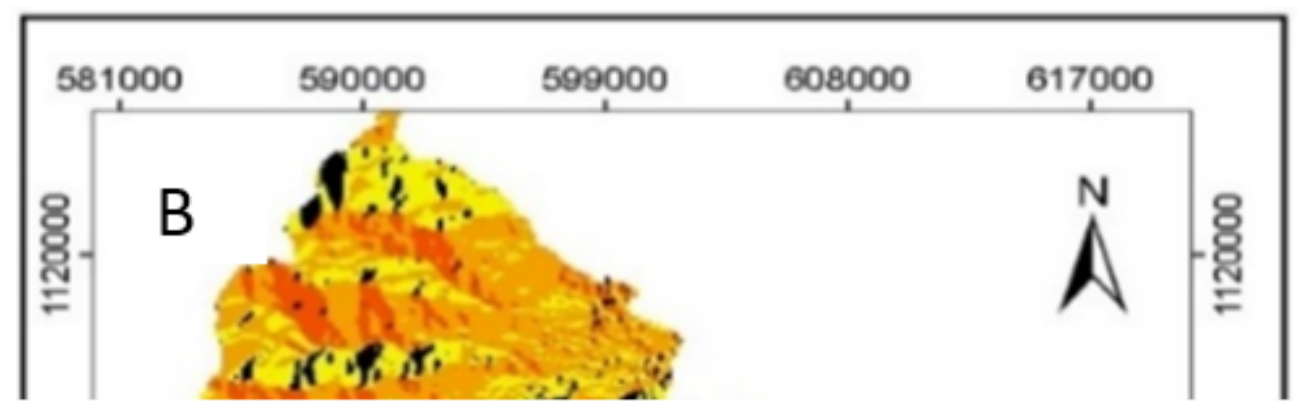

Figure 5

Suitability map of aspect 


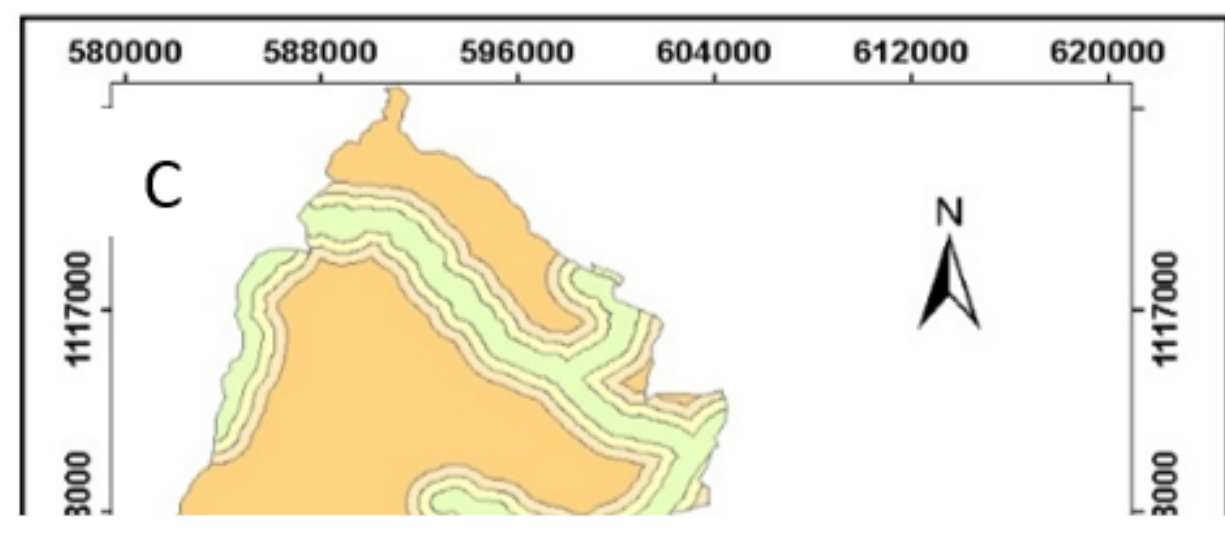

Figure 6

Suitability distance of the roads 


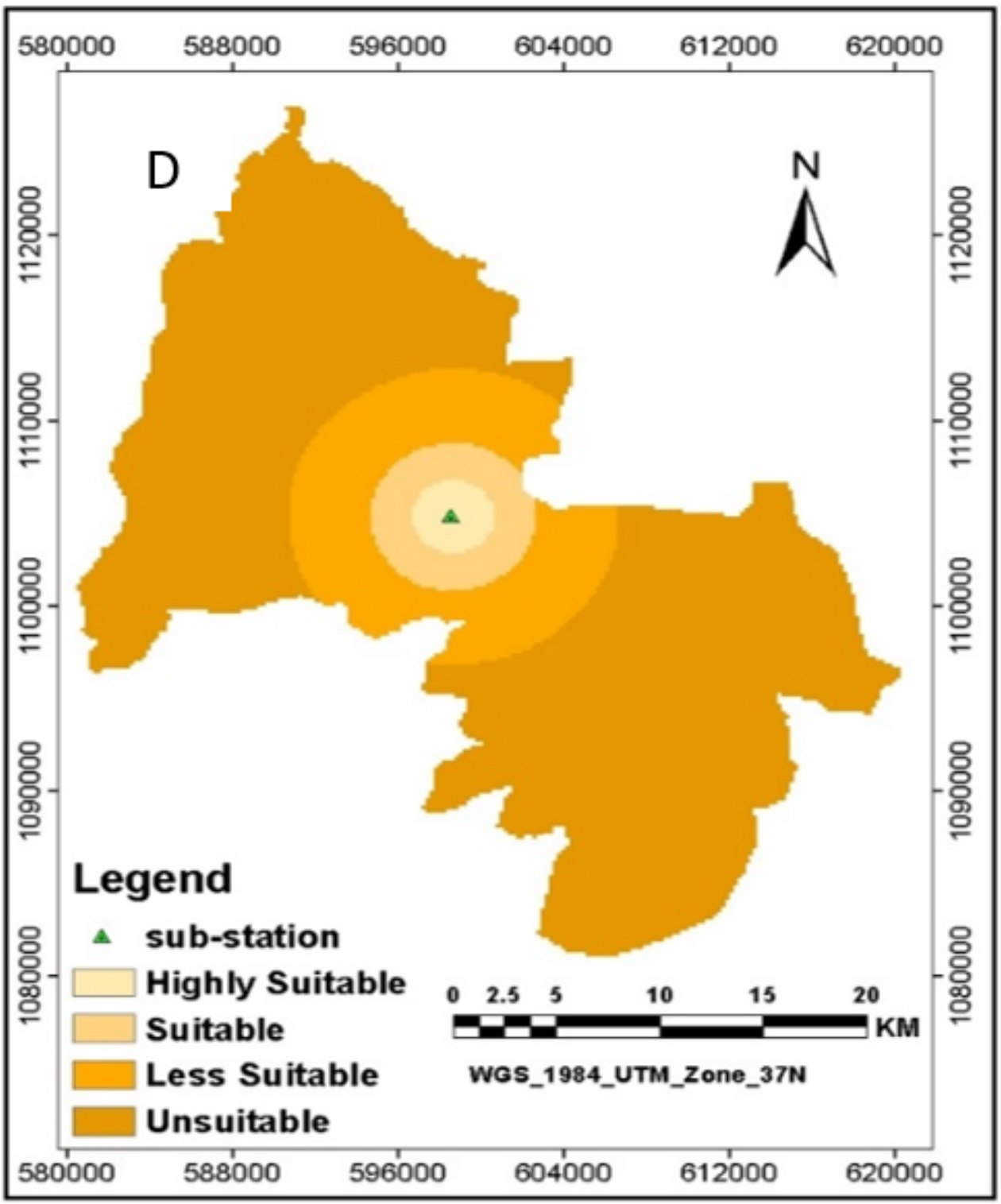

Figure 7

Suitability map of sub-station 


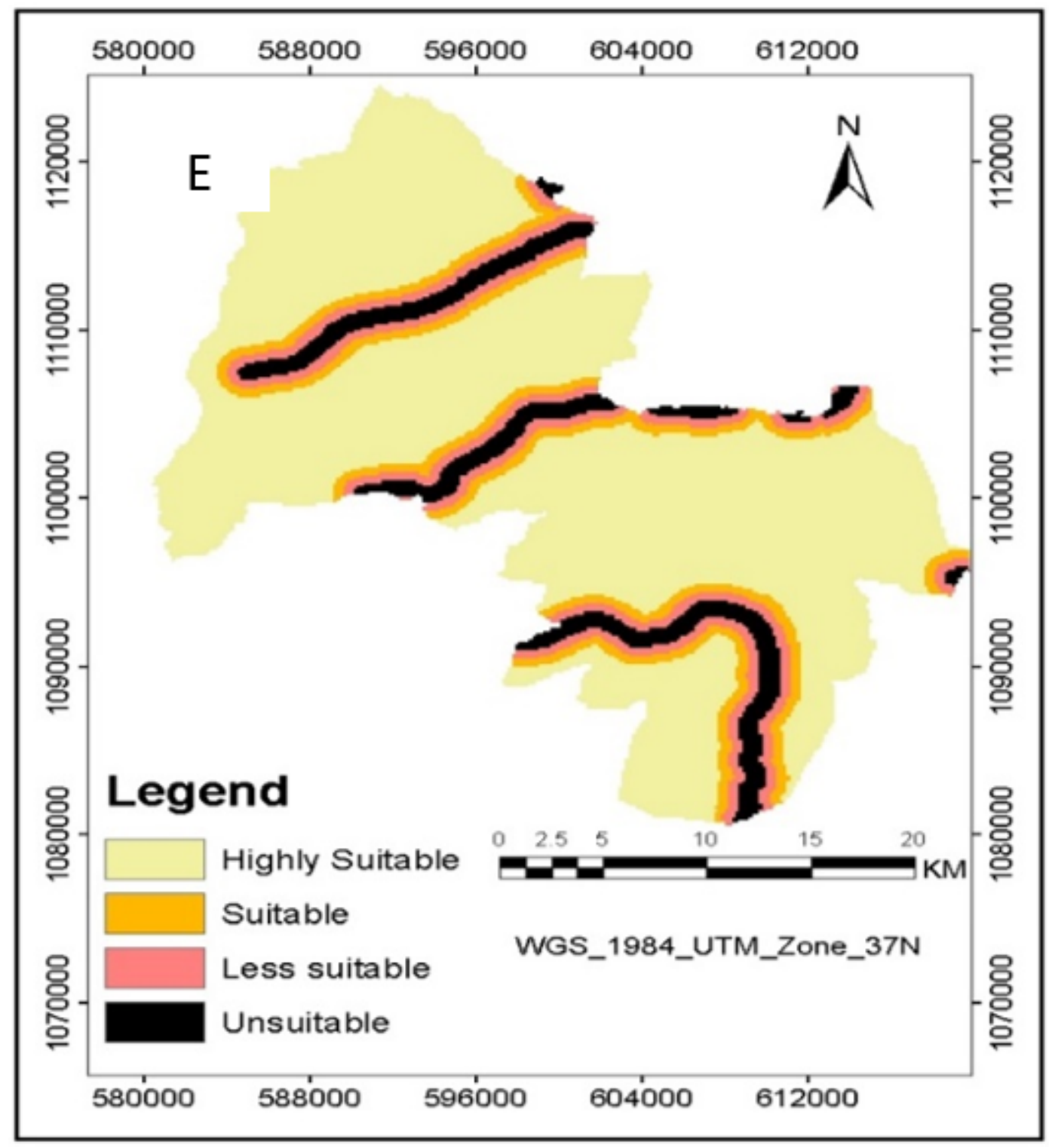

Figure 8

Suitability distance of river 


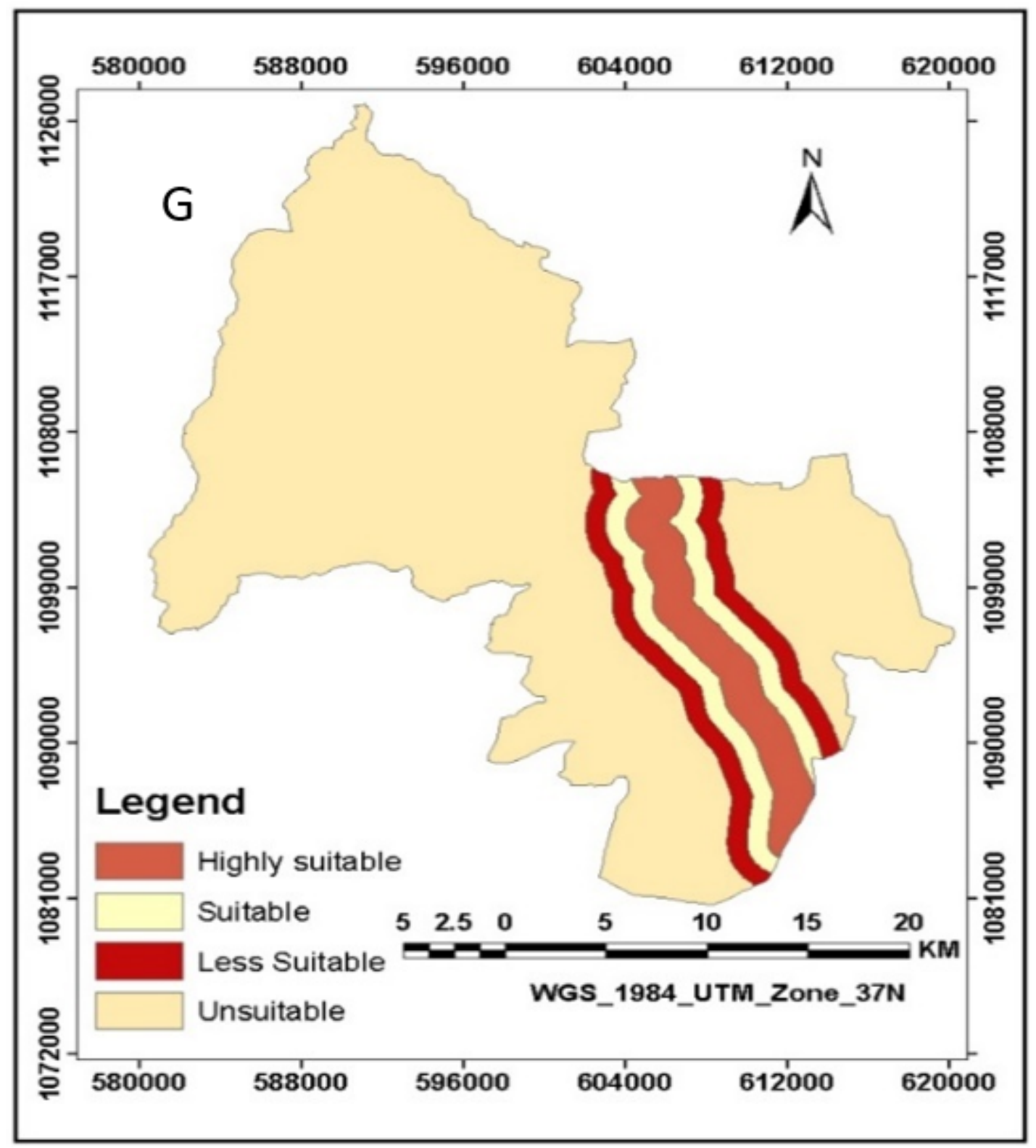

Figure 9

Suitability map of railway 


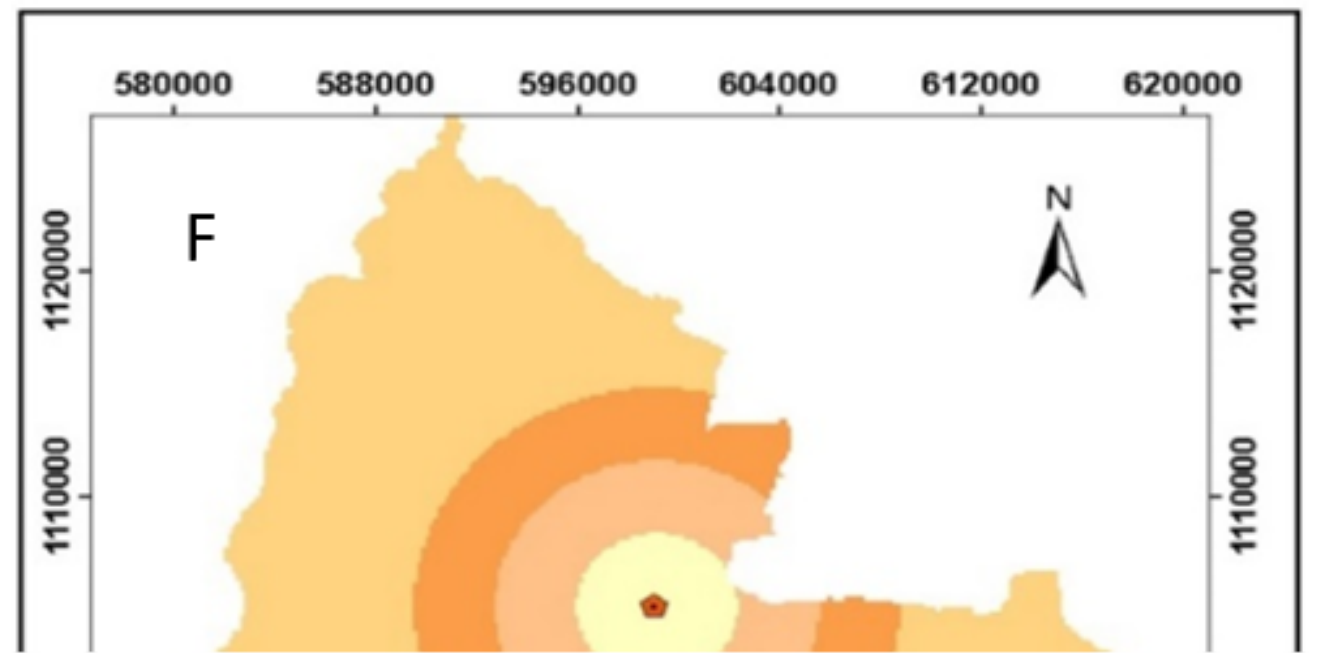

Figure 10

Suitability Map of town 


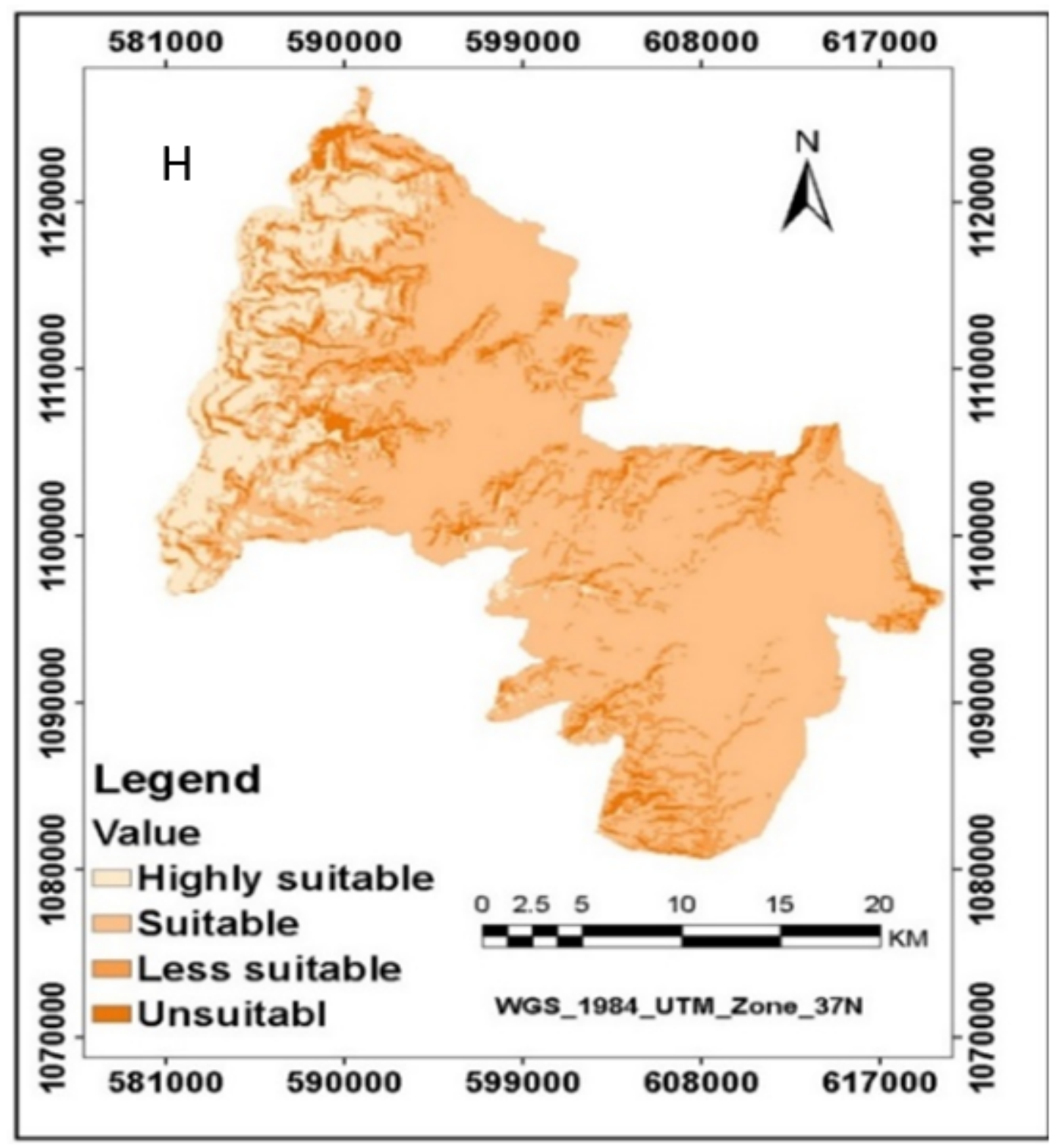

Figure 11

Suitability map of solar radiation 


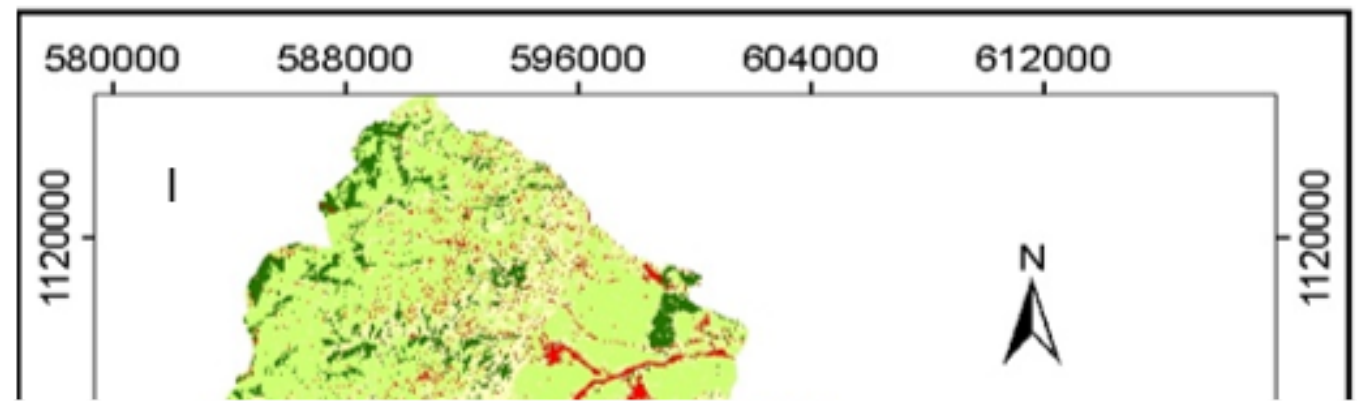

Figure 12

Suitability map of land use land cover 


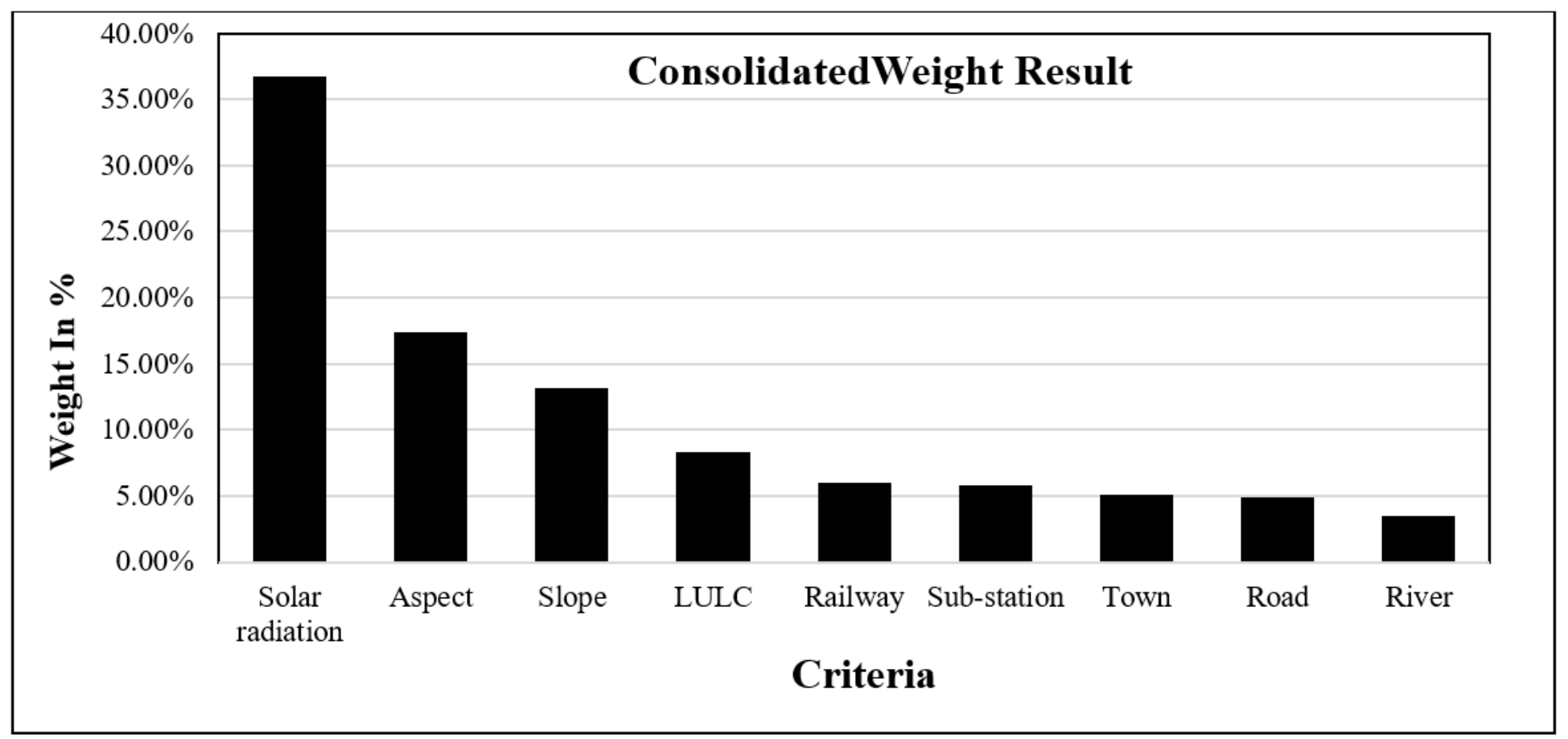

Figure 13

the output of the criteria weighted using by pairwise comparison matrix methods 


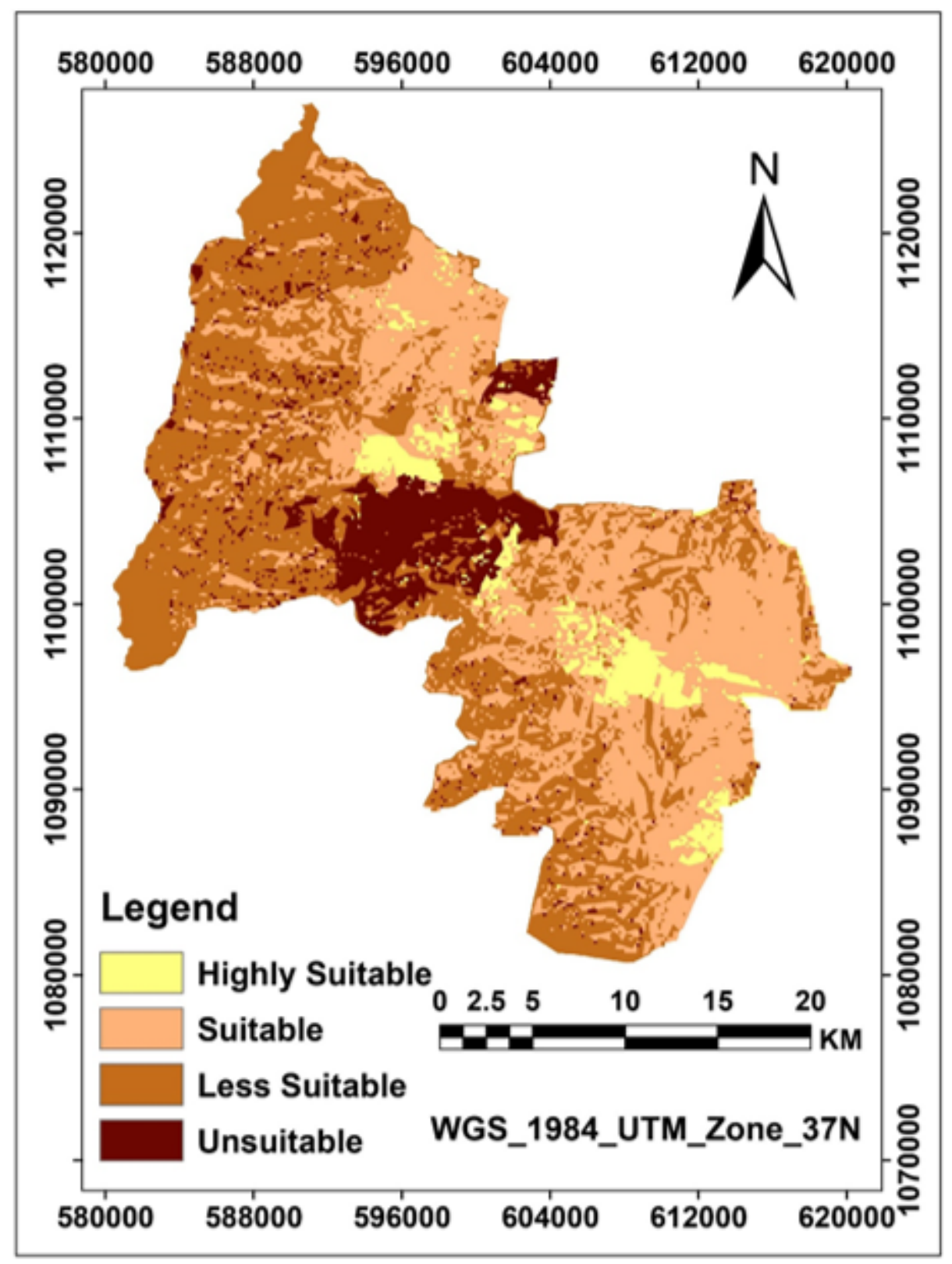

Figure 14

Suitable Map of the Study Area

\section{Supplementary Files}

This is a list of supplementary files associated with this preprint. Click to download.

- GraphicalAbstract.docx 